\title{
Guest Editorial - The Middle Palaeolithic in the Desert II
}

Research on Middle Palaeolithic occupations within the mid-latitude desert belt is enjoying a sustained surge of interest. This ongoing focus is in part because the mid latitude arid belt forms a shifting environmental barrier between different biogeographic zones. Ecological flux within these desert regions have therefore modulated human dispersals both temporally and spatially. Until recently, broad-brush models of human adaptation and expansion have been coarsely framed within such environmental frameworks, and typified by the reduction of past population dynamics to arrows on maps covering vast landscapes. More nuanced patterns of past population dynamics are now being identified that also expose the complexities of early human demography. Specifically, dramatic advances in complementary disciplines, namely genetics and climate science, have helped to expose past patterns of human demography and expansions in ever increasing resolution. While the skeletal record of the mid-latitude arid belt includes both Homo sapiens and Neanderthals, an increasingly complex demographic picture is becoming evident from genetic research, which break down simple dichotomies between 'modern' and 'archaic'. From a cultural perspective, these identifications have emphasized the increasing need to focus on population-level studies, acknowledging the complexities of the relationship between material culture and biology. Such archaeological approaches can reliably ground their analyses in terms of geography, past environments and, most importantly, time, none of which can be simply achieved through genetic approaches. Furthermore, archaeological research permits the examination of when and where major population expansions occurred, and also how they were achieved. Combining these different approaches is key, with each discipline helping to identify new foci of study in the others.

This volume brings together a selection of papers resulting from the Middle Palaeolithic in the Desert II conference, hosted by UMR5199 PACEA, Université de Bordeaux in December 2014. The papers in this volume reflect both the international make-up of attendees and the interdisciplinary approaches that have been employed. The papers can be split broadly into intensified analyses in existing centres of research from the central Sahara to the Levant, and exploration of new landscapes, particularly at the extremities of the desert belt. We are pleased to see the continuing progress of research on the Middle Palaeolithic in the desert since our first conference and edited volume on the theme (Groucutt and Blinkhorn, 2013).

Perhaps particularly unique to this volume, is the contribution of three papers on the Palaeolithic of Senegal. The Pleistocene archaeology of West Africa has long been a terra incognita of the African Stone Age, not least because it has been considered beyond the main stage of human evolution in East Africa. The contributions from Niang and Ndiaye (this issue), Chevrier et al. (this issue) and Scerri et al. (this issue) cover southeastern, southwestern and northern Senegal respectively and together mark a new focus on Senegal as a key region for human origins research. Although Senegal, at the boundary between subSaharan and North Africa, has been investigated before by both French and Senegalese teams, recent genetic and palaeoclimatological evidence have brought the area into the spotlight. The three papers on Senegal reveal that the new focus on the region is certainly justified.

All three papers report on new fieldwork results in Senegal. Niang and Ndiaye (this issue) focus on a re-evaluation of the material from the southwestern locality of Tiemassass, which was first reported on by Dagan. The chronological and cultural character of the material from Tiemassass has long been the subject of debate, but has never been comprehensively 
analysed. Niang and Ndiaye (this issue) undertake this critical first step as part of a new fieldwork project re-investigating Tiemassass. They find considerable Middle Stone Age (MSA) material alongside artefacts from later periods, indicating that the Tiemassass area was important throughout prehistory. They report that the assemblage is flake dominated, generally characterized by typical MSA methods such as Levallois, opportunistic and discoidal flaking, and more rarely by laminar methods. Of particular interest here are tanged tools, which closely resemble those from MSA assemblages in North Africa. While chronometric dates are not yet available for this locality, the scale and technological diversity associated with this river are a sure indication that important information will be obtained from the new investigations at Tiemassass.

Until further information clarifies the archaeology of Tiemassass, the debate on the presence of MSA tanged tools in Senegal has received new data. Scerri et al. report the as yet undated presence of tanged tools in northern Senegal in unmixed, culturally MSA contexts. Indeed, Scerri et al.'s (this issue) report on ten new MSA sites in the Senegal River Valley, emphasises the rich potential of the archaeology across the region. Techno-typology appears to be particularly homogenous in the northwest of the Senegal River Valley, which gradually slopes into what may have comprised the maximum extent of interglacial marine introgression. Finely made chert implements include Levallois points and flakes, denticulates, basally thinned pieces, core axes and possibly tanged or shouldered tools.

Significantly, the climate models reported by Scerri et al. (this issue) suggest that the Senegal region did not suffer the dramatic climatic shifts experienced in North Africa. The sites discovered along the southern edges of the Sahara may therefore represent human habitation in a refugial zone, where it seems the Senegal River's flow did not cease, even during arid periods. However, Scerri et al. (this issue) also see links to central Africa, suggesting that the Senegal hydrological network facilitated population movement between both northern and central Africa. The high degree of technological variability across Senegal is certainly consistent with such a hypothesis, along with the continued importance of the Senegal region throughout the Stone Age.

Chevrier et al.'s (this issue) contribution reinforces preliminary hypotheses on the role of the Senegal region in facilitating human dispersals and population turnovers. They report initial chronometric dates and associated discoveries from southeastern Senegal, in the Faleme region. Field survey allowed the discovery of a very large number of sites in this region, some in primary context. This work again emphasizes the potential of archaeological research in Senegal. Chevrier et al. (this issue) draw particular attention to the sites of Ravin des Guêpiers, Fatandi, Toumboura and Missira which feature assemblages using different techniques dating to the Late Pleistocene and Early Holocene. The presence of such different techniques within a relatively small time bracket gives important insights into complex demography during periods of major environmental transition. As much of North Africa experienced severe aridity during MIS 2, the presence of people just south of the arid zone supports the climate models reported in Scerri et al. showing that the Senegal region was environmentally stable, and a probable refugium.

The Hauh Fteah, North-East Libya, plays an important role in our understanding of MSA variability across northern Africa, yet the surrounding landscape is also rich in archaeological sites. Jones (this issue) provides details of a number of surface sites identified across the Gebel Akhbar, for which a clear chronology is lacking. By employing a range of multivariate statistical approaches, Jones (this issue) examines core technology spanning the early MSA to 
early LSA, aiming to assess whether common technological patterns could help build a relative chronology for surface sites in the region. The aims, hypotheses and methods employed along with appropriate caveats to undertake this are set out clearly, making this a good example of the application of multivariate statistical methods in lithic analyses that is accessible to those unfamiliar with the specific approaches employed. Two key trends identified are that amongst a backdrop of common core technologies in classic MSA assemblages, greater diversity can be observed across the Gebel Akhbar landscape, whereas misclassification of cores from the early MSA (Pre-Aurignacian) and early LSA (Dabban) levels at Hauh Fteah, suggest similar misclassification is likely to have occurred at other sites within the landscape. The results do not offer a straight forwards means to integrate surrounding surface sites into the Hauh Fteah sequence, but offer the first steps to explore patterns of cultural and population continuity and change in this important landscape.

Garcea (this issue) focuses on the problems associated with simplistic inferences of archaeological, fossil and genetic data relating to the dispersals of Homo sapiens out of Africa. Different environmental windows transforming the arid environments of North Africa and parts of southwest Asia facilitated multiple dispersals which she has grouped into two broad 'early' and 'late' categories. By using a biogeographic perspective, archaeological differences both across North Africa and between this region and sub-Saharan Africa are summarised, and an evaluation of genetic evidence to support alternate theories regarding human dispersal and interbreeding is presented. Although inferences are still limited by low spatial and chronological resolution, the emerging picture is a complicated one, in which many of the old certainties are no longer tenable. The key point Garcea (this issue) makes is that both biological and cultural evolution, as well as dispersal trajectories, are not clear cut, with genetic exchange, innovation and expansion in both into and out of Africa occurring as a more continuous process then commonly envisaged.

Osypiński and Osypiński (this issue) report new data from the late Middle Palaeolithic (MP)/Middle Stone Age (MSA) locality of Affad 23, Sudan. While featuring many characteristics common to the MP/MSA, they report a series of optically stimulated luminescence (OSL) age estimates suggesting that the site dates to only 16-15 ka. Unlike sites from this time in areas such as lower Nubia, Affad 23 lacks features indicative of an Upper Palaeolithic (UP)/Later Stone Age (LSA) attribution. Extensive refitting of lithics in the excavated assemblage offer important insights into lithic technology at Affad 23, while faunal remains offer significant ecological and biogeographical insights. As well as reporting on a high resolution archaeological and palaeontological locality, the findings of Osypiński and Osypiński (this issue) demonstrate the considerable spatial and temporal complexity of the MP/MSA.

Kleindienst and colleagues (this issue) report a series of electron spin resonance (ESR) age estimates for Pleistocene faunal remains from Dakhleh Oasis, Egypt. Their results indicate that more humid conditions were repeatedly present at Dakhleh Oasis in the Middle and Late Pleistocene as well as the early Holocene, suggesting that human occupations could also have repeatedly occurred in the same timeframe. From the 1970's onwards the Dakhleh Oasis Project (DOP) has conducted interdisciplinary fieldwork at Dakhleh. While revealing a rich prehistoric record, previous research at the oasis has been limited by a lack of Pleistocene chronometric age estimates. Kleindienst and colleagues (this issue) paper therefore offers a valuable geochronological database, providing evidence for repeated northwards expansions of currently Sub-Saharan type environments and fauna. 
Goder-Goldberger and colleagues (this issue) paper reports on the discovery of 'Nubian' Levallois cores in the Levant. The meaning of 'Nubian' Levallois reduction, initially described as 'beaked' Levallois (Seligman, 1921), has been much debated (Groucutt et al., 2015). To proponents, the presence of this technology is southwest Asia provides strong evidence for the dispersal of Homo sapiens out of Africa in MIS 5. An alternative view suggests that convergent evolution may explain similarities between some aspects of lithic technology in different areas. While different interpretations of Goder-Golberger and colleagues (this issue) findings are possible, the presence of a recently prominent form of technology is significant in the context of recent debates. Previously 'beaked' Levallois cores had only been reported from sporadic occurrences in Levantine MP assemblages. GoderGoldberger and colleagues (this issue) report the recognition of 28 of them from the Negev. If one sees these core types - or more precisely the reduction sequences leading to these core types - as a 'guide fossil' for Homo sapiens, then this finding suggests that dispersal out of Africa need not have exclusively involved a 'southern' route across the Red Sea. GoderGolberger and colleagues (this issue) also emphasise that cultural diffusion, rather than simply population dispersal, may be involved in spreading technological similarities. The debate on the meaning of 'beaked' Levallois technology is likely to remain unresolved until detailed comparative studies of chronometrically dated lithic assemblages are conducted.

Nasab and Hashemi (this issue) report on recent fieldwork from the Iranian Central Desert, focusing upon the site of Chah-e Jam. A belt of playas is spread across the Iranian Central Desert, and it is only recently that the importance of examining these now dry, saline lake beds has come into focus. Nasab and Hashemi (this issue) set out how the geographical location of the region makes it an important Palaeolithic cross roads, following up on the work of Nasab et al. (2013) from the previous Middle Palaeolithic in the Desert volume. Here, artefact assemblages from the edge of Chah-e Jam lake are presented and compared with other Palaeolithic sites within the region. Middle Palaeolithic technologies in the Iranian Central Desert are reported as distinct from the Zagros industries, and limited Upper Palaeolithic presence is also noted. While it is not currently possible to integrate this into a clear chronological framework, habitation at Chah-e Jam is most likely to have occurred during humid phases, and resolving the timeframe for lacustrine activity in the Iranian Central Desert will have important implication for examining mobility and population expansions at this major continental crossroads.

James Blinkhorn

McDonald Institute for Archaeological Research, University of Cambridge

Eleanor Scerri

Research Laboratory for Archaeology and History of Art, School of Archaeology, University of Oxford

Huw Groucutt, Research Laboratory for Archaeology and History of Art, School of Archaeology, University of Oxford

Anne Delagnes

CNRS, UMR 5199 PACEA, Université de Bordeaux 


\section{Acknowledgements:}

We would like to acknowledge the support of many members of PACEA who helped to arrange the December 2014 conference, and particularly Catherine Morell-Chevillet, JeanFrancois Caro and Michelle Charuel for their administrative support. We would also like to thank Brad Gravina for making the conference fieldtrip to the Dordogne a roaring success due to his enthusiastic, informative and engaging introductions to the sites we visited. We are grateful for the financial support of the PACEA, CNRS, LabScArEx, the Universite de Bordeaux and Beta Analytic, which was critical not only to hold the conference but importantly to support attendance and participation of scholars from lower-income countries, including India, Iran and Senegal. Blinkhorn and Scerri acknowledge the support of the Fondation Fyssen and PACEA during their post-doctoral research in Bordeaux. Finally, we offer our thanks to Prof Norm Catto, alongside his editorial team at Quaternary International, for his support in publishing both volumes of Middle Palaeolithic in the Desert.

\section{References:}

Chevrier, B., Rasse, M., Lespez, L., Tribolo, C., Hajdas, I., Fígols, M.G., Lebrun, B., Leplongeon, A., Camara, A., Huysecom, E. West African Palaeolithic history: New archaeological and chronostratigraphic data from the Falémé valley, eastern Senegal. Quaternary International, this issue.

Goder-Goldberger, M., Gubenko, N., Hovers, E. "Diffusion with modifications": Nubian assemblages in the central Negev highlands of Israel and their implications for Middle Paleolithic inter-regional interactions. Quaternary International, this issue.

Garcea, E.A.A. Dispersals Out of Africa and Back to Africa: Modern Origins in North Africa. Quaternary International, this issue.

Groucutt, H.S., Petraglia, M.D., Bailey, G., Scerri, E.M.L., Parton, A., Clark-Balzan, L., Jennings, R.P., Lewis, L., Blinkhorn, J., Drake, N.A., Breeze, P.S., Inglis, R.H., Deves, M.H., Meredith-Williams, M., Boivin, N., Thomas, M., Scally, A., 2015. Rethinking the dispersal of Homo sapiens out of Africa. Evolutionary Anthropology 24, 149-164

Groucutt, H.S., Blinkhorn, J., 2013. Guest editorial: The Middle Palaeolithic in the desert and its implications for understanding hominin adaptation and dispersal. Quaternary International 300, 1-12.

Jones, S. C. Middle Stone Age reduction strategies at the desert's edge: A multi-site comparison across the Gebel Akhdar of northeast Libya. Quaternary International, this issue.

Kleindienst, M.R., Blackwell, B.A.B., Skinner, A.R., Churcher, C.S., Kieniewicz, J.M., Smith, J.R., Wise, N.L., Long, R.A., Deely, A.E., Blickstein, J.I.B., Chen, K.K.L., Huang, C.A., Kim, M.Q.D., this issue. Assessing long-term habitability at an eastern Sahara oasis: ESR dating of molluscs and herbivore teeth at Dakhleh Oasis, Egypt. Quaternary International, this issue.

Nasab, H.V., Clark, G.A., Torkamandi, S., 2013. Late Pleistocene dispersal corridors across the Iranian Plateau: A case study from Mirak, a Middle Paleolithic site on the northern edge of the Iranian Central desert (Dasht-e Kavir). Quaternary International 300, 267-281. 
Nasab, H. V., Hashemi, M. Playas and Middle Paleolithic Settlements at the Iranian Central Desert: Discovery of Chah-e Jam Middle Paleolithic Site. Quaternary International, this issue.

Niang, K., Ndiaye, M. The Middle Palaeolithic of West Africa: Lithic techno-typological analyses of the site of Tiemassas, Senegal. Quaternary International, this issue.

Osypiński, P., Osypiński, M., this issue. Optimal adjustment or cultural backwardness? New data on the latest Levallois industries in the Nile Valley. Quaternary International, this issue.

Scerri, E.M., Blinkhorn, J., Groucutt, H.S., Niang, K., 2015. The Middle Stone Age archaeology of the Senegal River Valley. Quaternary International, this issue

Seligman, C.G., 1921. The Older Palaeolithic Age in Egypt. The Journal of the Royal Anthropological Institute of Great Britain and Ireland 51, 115-153. 